\title{
Clinical Manifestation, Surveillance, and Complication in Tuberous Sclerosis Complex in Dr. Moewardi Hospital
}

\author{
Baarid Luqman Hamidi, Diah Kurnia Mirawati, Rivan Danuaji, Subandi, \\ Pepi Budianto, Yetty Hambarsari, Hanindya Prabaningtyas \\ Department of Neurology, Dr. Moewardi Hospital/ \\ Faculty of Medicine, Universitas Sebelas Maret
}

Background: Tuberous Sclerosis Complex (Bourneville's disease) is genetic disorder with autosomal pattern of heritence that affecting differentiation sellular in many organ such as brain, lungs, cardiac with varible severity. Birth incidence is estimated to be 1:600o. The purpose of this study was to reported a case of patients with Bourneville's disease (tuberous sclerosis complex) in Moewardi Hospital. Also reported surveillance and complication in this patient. Case Presentation: A male, 18 yearsold, with seizures, onset from infancy, tonic secondary generalized seizure pattern simultaneously throughout the body. Neurologic status examination found right hemiparese and mental retardation, Encountered in patients with skin disorders such as butterfly appearance with facial angiofibroma, forehead fibrous plaque dan shargreen patch. Abnormalities also appeared in the oral mucosa as multiple papules. When psychological tests patient had difficulty following instructions. Psychiatric examination showed moderate lower intelegence. EEG results slow waves at left parietal, there is severe electrofisiologic abnormality considered structural lesion in left parietal. CT showed multiple calcified nodules in subependymal right and left lateral ventri- cle. MRI showed atrophy and left sclerotic hippocampus with glosis in sub cortex occipito left parietal. To overcome the seizure patients given Carbamazepine. There was increasing of transaminase enzim, liver suspect liver angiomyolipoma.

Conclusion: Based on clinical criteria for definite tuberous sclerosis complex patients met the criteria. The patients responded positively to carbamazepine that reduced seizure frequency. But somehow, patient's prognosis is worst. Presence of intellectual impairment and neuropsychiatric problems is a potential poor epilepsy control, and liver disfunction so that the necessary comprehensive management and surveillance involves other disciplines.

Keywords:Tuberous sclerosis complex, congenital disorder, epilepsy, mental retardation

\section{Correspondence:}

Baarid Luqman Hamidi.Department of Neurology, Dr. Moewardi Hospital/Faculty of Medicine, Universitas Sebelas Maret. Email: baarid@staff.uns.ac.id

Cite this as:

Hamidi BL, Mirawati DK, Danuaji R, Subandi, Budianto P, Hambarsari Y, Prabaningtyas H (2020). Clinical Manifestation, Surveillance, and Complication in Tuberous Sclerosis Complex in Dr. Moewardi Hospital. Indones J Med. 05(01): 47-51. https://doi.org/10.26911/theijmed.2020.05.01.07

cc (i) (-) Indonesian Journal of Medicine is licensed under a Creative Commons

cc)

BACKGROUND
Tuberous Sclerosis Complex (TSC) or also
called Bourneville disease is an autosomal
dominant genetic disease that involves multi-
organ disorders involving the brain, skin,
kidneys, liver, lungs, heart, and in some cases
may involve the retina, ginggiva, bone and digestive system (Curatolo et al., 2018; Krueger et al., 2013; Northrup et al., 2013). Sherlock then introduced this syndrome as a trier of Tuberous sclerosis with the abbreviation EPILOIA (Epi: epilepsy, Loi: Low Intelligence, A: Adenoma sebaceum) (De 
Hamidi et al./ Clinical manifestation and complication in tuberous sclerosis complex

Waele et al., 2015; Sarkar et al., 2016). This syndrome is very important in the neurology because more than $90 \%$ of TSC patients develop neurological symptoms such as epilepsy, austism spectrum disorders (ASDs), intelligence disorders, sleep disorders, behavioral disorders, TSC-related neuropsychiatric disorders (TAND) which cause separate problems in patients and patient family(Jülich and Sahin, 2014).

This genetic disease is rare with an increase in the number of events each year. The incidence rate is $1: 6,000-100,000$ per live birth and the prevalence in the population reaches 1: 20,000 (Curatolo, 2015; Curatolo et al., 2018; Krueger et al., 2013; Northrup et al., 2013). This disease is often difficult to diagnose due to a variety of phenotypic symptoms. It is important for data for the Asia Pacific region to be very limited, but in studies in Taiwan populations it is stated that there are similarities in the distribution of phenotypes and mutations with the Caucasian race(Lawson et al., 2014).

Considering the variety of clinical presentations and their exposure to many organs, as well as the development of diseases that will occur during life, it is necessary to establish accurate and early diagnosis, integrated management, and continuous clinical monitoring so that they can recognize complications early and proactive management so as to reduce mortality and mortality morbidity of patients with tuberous scleosis complex. The International Tuberous Sclerosis Complex Concensus Conference 2012 (Northrup et al., 2013) published several recommendations for new diagnostic criteria, including more comprehensive and sustainable management and supervision of disease development.

\section{CASE PRESENTATION}

Patient with his family come to the Neurology clinic of Surakarta Moewardi Hospital with a history of seizures. The patient has been routinely controlled at the Neurology clinic at the Moewardi Hospital in Surakarta since September 2014. During this time, the seizures were controlled, the patient has not had seizures for the past 11 months. Patients take carbamazepin $200 \mathrm{mg}$ twice a day regularly.

Previously, in early September 2014 the patient had experienced epilepticus refracter status because at that time the patient did not take anti-eplileptic drugs regularly. The patient have right hemisphere, the right hand is weaker than the right leg. Patients have a history of uncontrolled seizures since childhood, disappear, arise spontaneously, each seizure about 1-2 minutes. The patient experiences mental retardation, a development that is late compared to children his age. Behavior and intelligence of patients such as children aged 4 years, until now a special school. Patients can be invited to communicate even though it is limited. Can answer simple questions and can explain your own identity.

Patients have skin disorders such as butterfly appearance with angiofibroma facial (Figure1), forehead fibrous plaque (Figure2) and shargreen patch (Figure3). Abnormalities also appear in the oral mucosa as multiple papules. The histopathological findings showed perifollicular fibrosis \& dilatation of blood vessels, supporting the appearance of angiofibroma (Figure4, 5).

EEG results indicates slow waves at the left parietal region, there is severe electrophysiologic abnormalities considered structural lesion in the left parietal brain. CT-scan showed multiple calcified nodules in subdependent right and left lateral ventricles (figure6), with lateral ventriculomegaly.

MRI showed atrophy and sclerosis of the left hippocampus, hemiatrophy in left hemisphere with glyosis in left perilateral ventricular subcortex occipitoparietal region, lateral ventriculomegaly with sub ependymal 
Hamidi et al./ Clinical manifestation and complication in tuberous sclerosis complex

calsificasion (figure7,8). Abdominal ultrasound found fatty liver and inguinal lymphadenopathy. There was an increase in trans-

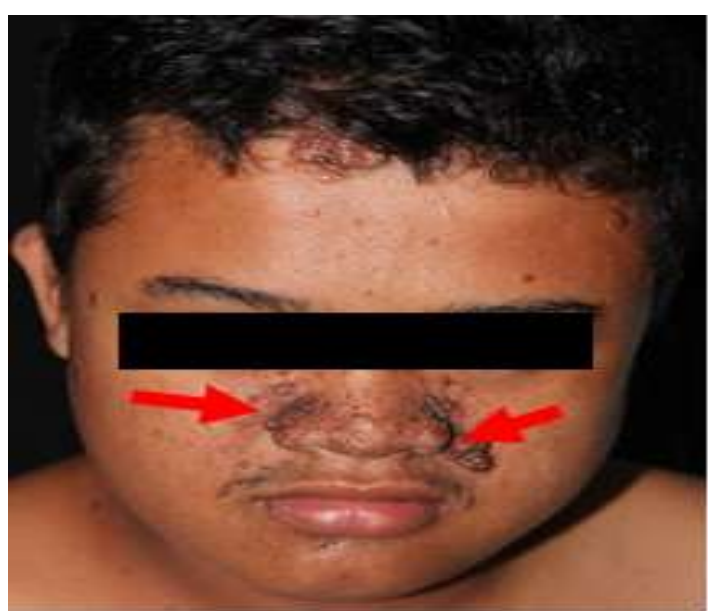

Figure1. Angiofribrima in regio facialis

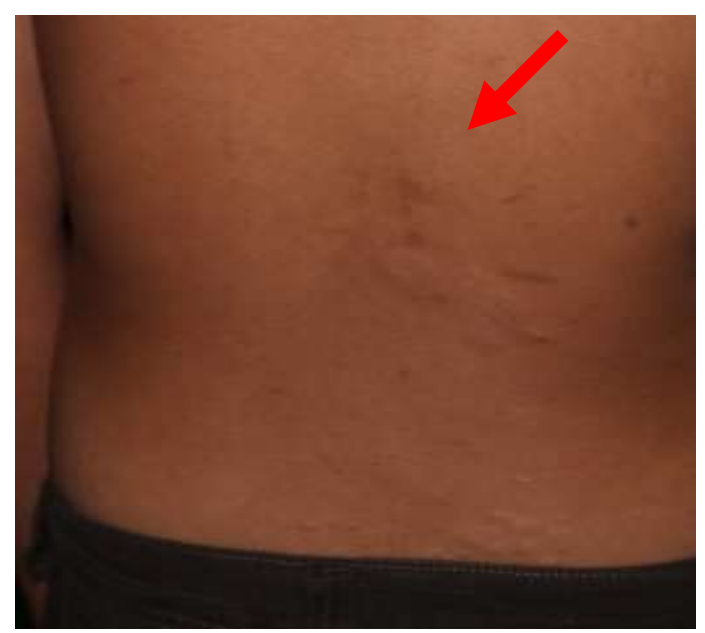

Figure 3. Shargreen patch

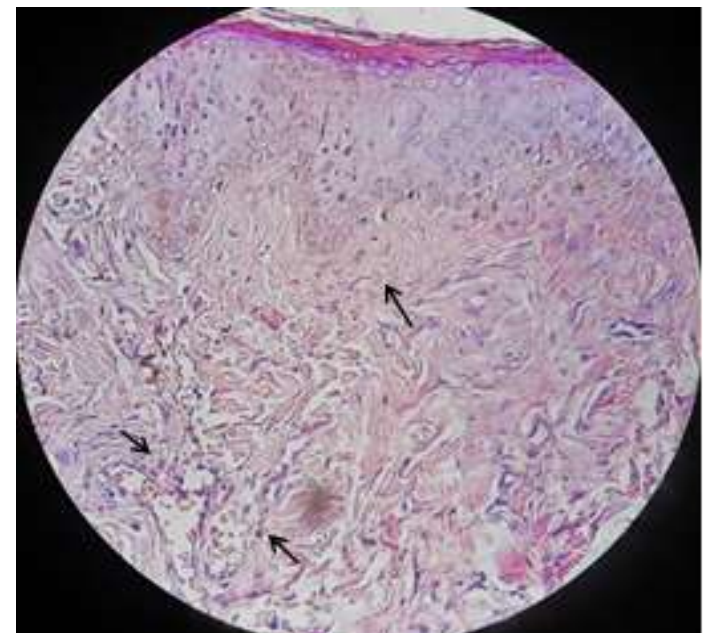

Figure 5. Perifollicular fibrosis and dilatation of blood zooming aminase enzymes, suspected angiomyolipoma in liver.

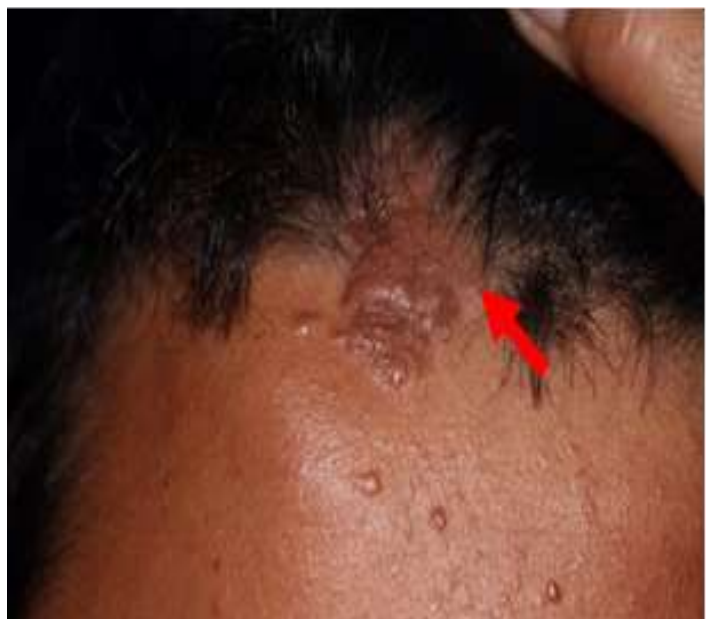

Figure 2. Forehead fibrous plaque

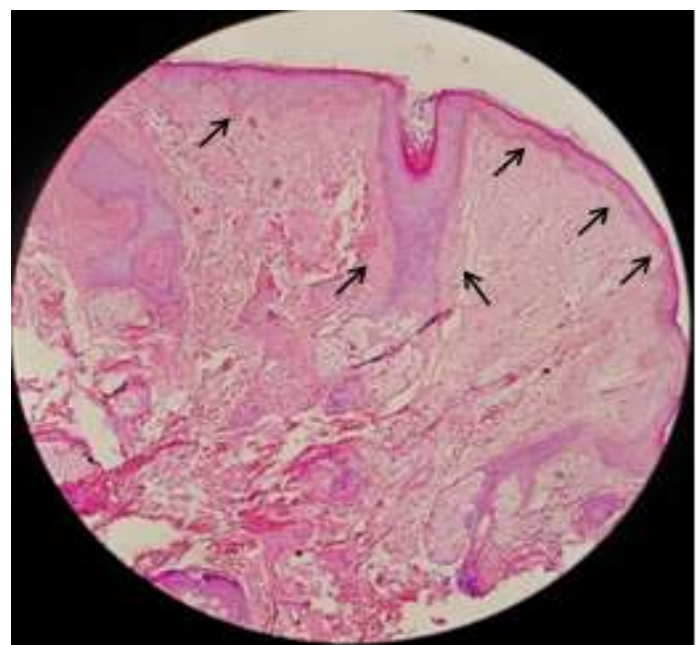

Figure 4. Perifollicular fibrosis and dilatation of blood vessels

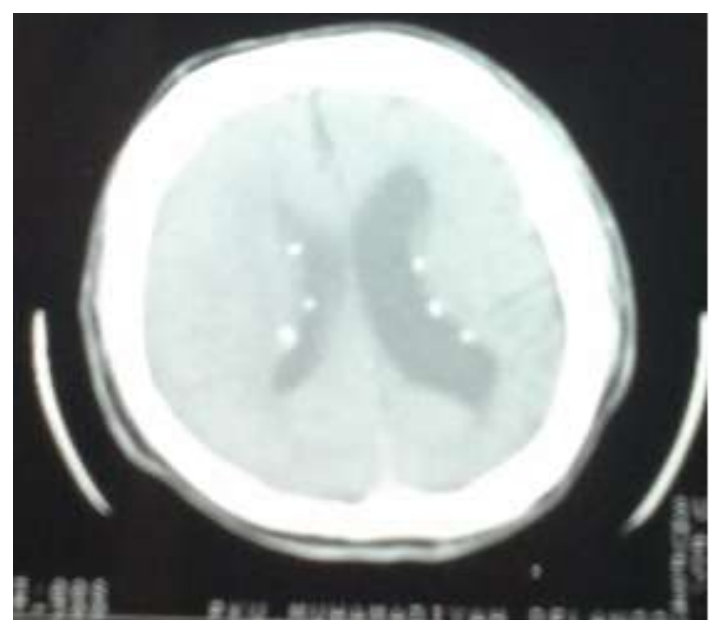

Figure 6. Nodul Calsificasion multiple in subependymal 
Hamidi et al./ Clinical manifestation and complication in tuberous sclerosis complex

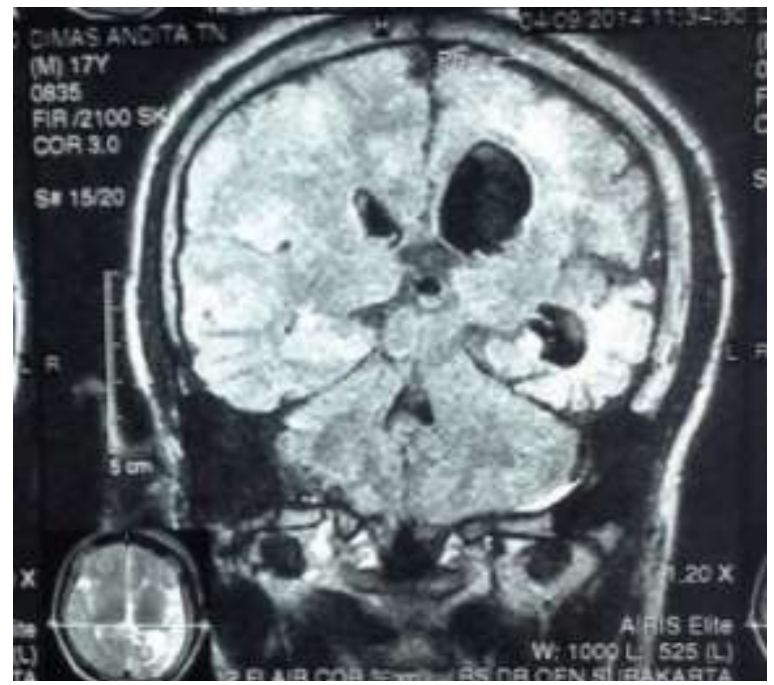

Figure 7. Atrophy and sclerosis in left hipocampus

Summarizing his past history, extensive physical signs and investigations, the final diagnosis of Tuberous Sclerosis Complex was made. He remained was ultimately discharged on carbamezapine $200 \mathrm{mg}$ twice a day.

\section{DISCUSSION}

It can be concluded from the history of the disease, collection of symptoms, a series of investigations, and obtained major clinical signs that support the diagnosis of tuberous sclerosis in accordance with the criteria, namely angiofibroma facialis, shargreen patch, Subdependent nodules on CT scan, cortical tuber on MRI, then clinically erect diagnosis of tuberous sclerosis.

In otherwise, in this patient there is a complication that is an increase in transaminase and fatty liver enzymes on ultrasound, there is a possibility of angiomyolipoma in the liver. On the other hand, administration of carbamazepin has the potential to cause hepatotoxicity. It is necessary to monitor liver function periodically.

Surveillance and management of TSC patients who have been diagnosed as definite or possible TSCs based on Recommendations of the 2012 International that have been

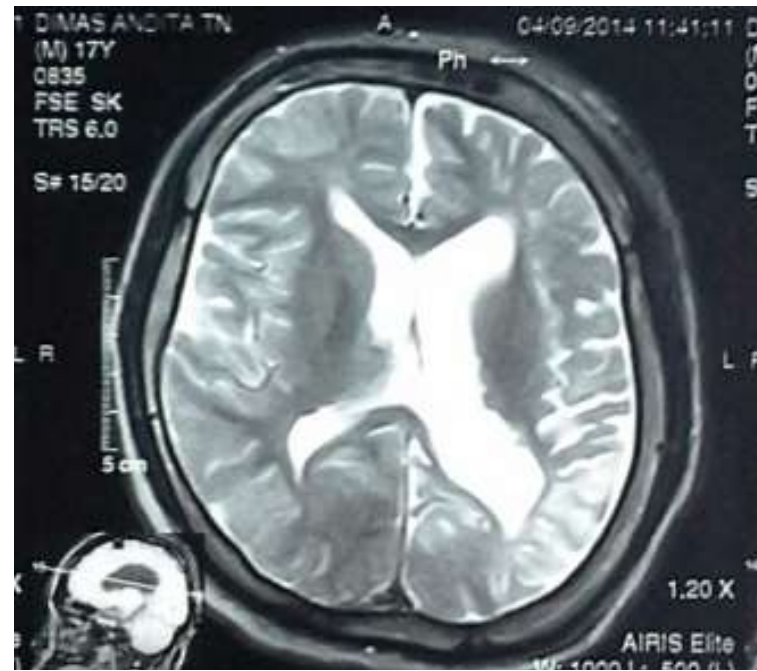

Figure 8. Hemiatrophy hemisfer sinistra dengan gliosis peri

adjusted for tuberous sclerosis patients in this case, so as to reduce morbidity and mortality.

This case study concludes that in this patient there are 4 major signs of TSC diagnostic criteria, namely: angiofibroma $(>3)$ or fibrous cephalic plaque, Shargreen patch, cortical diplasia, subodimal nodules from clinical manifestations of multiple organ systems, including the brain, skin, and liver.

Comprehensive and continuous management of multiorgans that are potentially involved is needed in order to properly diagnose TSC, so that lifelong supervision, good education, and early identification of complications can be carried out.

The selection of antiepileptic drugs in TSC patients must be done carefully in order to achieve maximum synergy with minimal side effects. These patients have controlled seizures using carbamazepine while continuing to monitor liver function over time. need to be considered for the administration of sirulimus or everolimus immunosuppressants (mTOR inhibitors) which are the recommended first-line therapy (Curatolo et al., 2018; De Waele et al., 2015), and are included in the BPJS formulary. mTOR inhibitors have been shown to reduce the 
Hamidi et al./ Clinical manifestation and complication in tuberous sclerosis complex

frequency and severity of epilepsy and inhibit the development of tuberous slerosis in other organs (Curatolo, 2015).

\section{AUTHOR CONTRIBUTION}

Baarid Luqman Hamidi, Diah Kurnia Mirawati, Rivan Danuaji, Subandi, Pepi Budianto, Yetty Hambarsari, and Hanindya Prabaningtyas did physical examination and wrote the manuscript.

\section{CONFLICT OF INTEREST}

\section{None}

\section{FUNDING AND SPONSORSHIP}

None

\section{ACKNOWLEDGEMENT}

We would like to thank to Department of Neurology at Dr. Moewardi Hospital, Surakarta for giving permission to collect the data.

\section{REFERENCE}

Sarkar S, Khaitan T, Sinha R, Kabiraj A (2016). Tuberous sclerosis complex: A case report. Contemp Clin Dent. 7(2): 236-239. https://dx.doi.org/10.4103\%2Fo976-237X.183071

Curatolo P (2015). Mechanistic target of rapamycin (mTOR) in tuberous sclerosis complex-associated epilepsy. Pediatrneurol. 52(3): 281-289. https://doi.o$\mathrm{rg} / 10.1016 / \mathrm{j}$. pediatrneurol.2014.10.02 8

Curatolo P, Nabbout, R, Lagae L, Aronica, E, Ferreira JC, Feucht M(2018). Management of epilepsy associated with tuberous sclerosis complex: Updated clinical recommendations. Eur J Paediatr Neurol, 22(5): 738-748. https://doi.org/10.1016/j.ejpn.2018.05.006
De Waele L, Lagae L, Mekahli D (2015). Tuberous sclerosis complex: The past and the future.Pediatr Nephrol, 30(10): 1771-1780. https://doi.org/10.1007/s00467-014-3027-9

De Waele L, Lagae L, MekahliD, Syed KN, Sahin M, Bolton PF, Frost MD (2015). Mechanistic target of rapamycin (mTOR) in tuberous sclerosis complexassociated epilepsy. Pediatr Nephrol, 18(4): 281-289. https://doi.org/10.1016/j.ejpn.2018.05.006

JülichK,Sahin M (2014). Mechanism-based treatment in tuberous sclerosis complex. PediatrNeurol, 50(4): 290-296. https://doi.org/10.1016/j.pediatrneurol.2013.12.002

Krueger DA, Northrup H, Krueger DA, Roberds S, Smith K, Sampson J, Frost MD (2013). Tuberous sclerosis complex surveillance and management: Recommendations of the 2012 international tuberous sclerosis complex consensus conference. Pediatr Nephrol, 49(4): 255-265. https://doi.org/10.1016/j.pediatrneurol.2013.08.002

Lawson JA, Chan CF, Chi CS, Fan, PC, Kim HD, Kim KJ (2014). Managing tuberous sclerosis in the Asia-Pacific region: Refining practice and the role of targeted therapy. J Clin Neurosci, 21(7): 1180-1187. https://doi.org/10.1016/j.jocn.2013.06.029

Northrup H, Krueger DA, Roberds S, Smith K, Sampson J, Korf B (2013). Tuberous sclerosis complex diagnostic criteria update: Recommendations of the 2012 international tuberous sclerosis complex consensus conference. PediatrNeurol, 49(4): 243-254. https://doi.org/10.1016/j.pediatrneurol.2013.08.001 